\title{
Examination of Pre-Service Teachers' Stress Levels towards Academic Expectations and Goal Commitment in Terms of Various Variables
}

\author{
Yesim Bayrakdaroglu ${ }^{1 \rtimes}$ \\ Hakan Hekim ${ }^{2}$ \\ 'Department of Physical Education and Sports, Gumushane University, Gumushane, Turkey. \\ Email: yesimsongun@gumushane.edu.tr Tel: +904562331092 \\ -Physical Education and Sports Teacher Education, Graduate Education Institute, Sakarya University of \\ Applied Sciences, Sakarya, Turkey. \\ Email:hakan.hekim@hotmail.comTel: +902466160954
}

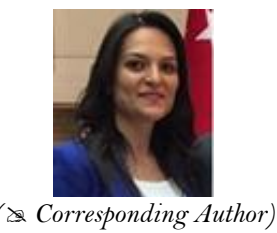

\begin{abstract}
This study was carried out with the aim of examining the stress levels towards academic expectations and goal commitment of pre-service teachers (students who are not yet teaching professionally) in terms of various variables. The data were obtained from pre-service teachers $(n=465)$ studying at a public university. In this study, two scales were used to collect data. One was the Academic Expectations Stress Inventory developed by Ang and Huan (2006) and adapted to Turkish by Akin, Abaci, and Cetin (2009). The other was the Goal Commitment Scale developed by Hollenbeck, Klein, O'Leary, and Wright (1989) in 9 items, revised in 5 items by Klein, Wesson, Hollenbeck, Wright, and DeShon (2001) and later adapted to Turkish by Senol and Turan (2019). Descriptive statistics, Independent T-test, One Way ANOVA, Pearson Correlation and Simple Linear Regression were used in the analysis of the data. As a result of the analysis, significant differences were found in the variable of the department in terms of "expectations of self" and "goal commitment" of pre-service teachers. Similarly, significant differences were found in the variable of academic grade average in terms of "expectations of self". In addition, it was observed that goal commitment levels and stress levels of "expectations of parents/teachers" of pre-service teachers were high. At the same time, it was observed that the stress level of "expectations of self" of pre-service teachers was above the middle level, but close to the high level.
\end{abstract}

Keywords: Goal commitment, Academic expectation, Stress, Pre-service teachers, Education, Academic stress.

Citation | Yesim Bayrakdaroglu; Hakan Hekim (2020). Examination of Pre-Service Teachers' Stress Levels towards Academic Expectations and Goal Commitment in Terms of Various Variables. Asian Journal of Education and Training, 6(3): 461-467. History:

Received: 23 April 2020

Revised: 29 May 2020

Accepted. 30 June 2020

Accepted: 30 June 2020

Published: 8 July 2020 is licensed under a Creative Commons

Attribution 3.0 License (cc) E

Publisher: Asian Online Journal Publishing Group
Acknowledgement: Both authors contributed to the conception and design of the study.

Funding: This study received no specific financial support.

Competing Interests: The authors declare that they have no conflict of interests.

Transparency: The authors confirm that the manuscript is an honest, accurate, and transparent account of the study was reported; that no vital features of the study have been omitted; and that any discrepancies from the features of the study have been omitted;
study as planned have been explained.

Ethical: This study follows all ethical practices during writing.

\section{Contents}

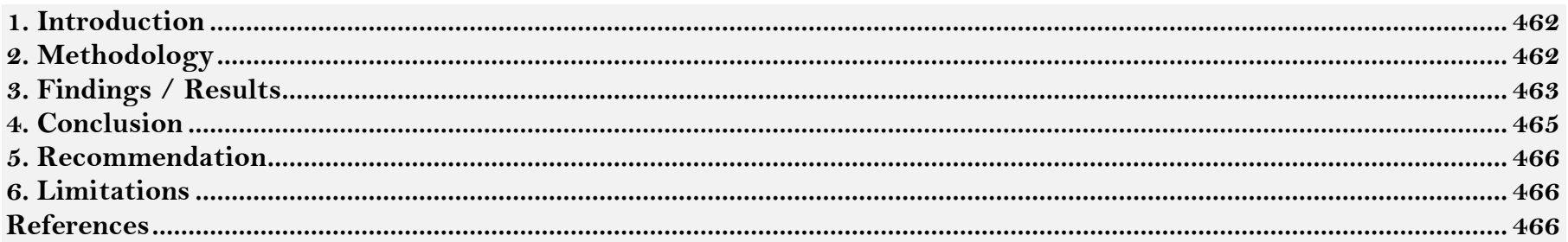




\section{Contribution of this paper to the literature}

The study is to determine the stress levels and target commitment levels of prospective teachers according to academic expectations. As a result, it contributes to the existing literature and examines it in terms of various variables.

\section{Introduction}

Nowadays, technological and scientific developments arising from globalization are reflected in education, therefore, expectations from education increase in this respect (Senol \& Turan, 2019). Education in the world is a very important element in terms of social development. Student success is an important outcome indicator in terms of achieving the educational goal (Epstein, 2018). However, the desire of educational administrators, teachers, families, and students to achieve academic excellence can be a source of intense stress for many students. In the literature, researches on students' social and cognitive development indicate that student-teacher interaction perceptions and family relationships affect their educational performance and academic success (Sengul, Zhang, \& Leroux, 2019). This situation can be the basic structure of academic stress on students. Academic stress appears to be a lifestyle crisis that occurs during the education process of students, especially during exam periods (Kadapatti \& Vijayalaxmi, 2012). Academic stress in the educational environment expresses the unpleasant situations that arise due to the many demands of the student's environment (Aihie \& Ohanaka, 2019). In other words, stress arises from the mismatch between supply and demand in the education mechanism. That is, if there is a difference between the expected success level and the resulting success level, there is a possibly stressful situation. At this point, whether the students consider the individuals they are in contact with or the events they experience as a source of stress is the main thing to consider (Tekin, Cilesiz, \& Gede, 2019). Students who have a successful education life will also contribute to the development of society with the culture they have Borekci and Uyangor (2018). If these elements are not considered as a source of stress, individuals do not experience stress either. Stress is an important factor that will not only affect education life, but also the working life of the individual (Kalkin, 2017).

The effects of all kinds of sources that cause stress response in the organism are stressors. Stressors can appear in different ways such as social events, psychological, physiological, biological, and life events. A significant part of the stressors covers life events (Barut, 2019). DeDeyn (2008) defined stress as a physical, mental, emotional reaction, or a reaction that requires adaptation, which occurs in case of difference. The physical symptoms caused by stress, when combined with the negative perspective of the individual, lead to more negative thoughts. Mental reactions in case of excessive stress occur in the thoughts and feelings of the individual (Kennerley, 2017). Expectations for students to be academically successful have been positively associated with success and excellence. On the other hand, excessive stress can lead to many features such as distraction and failure, and it can bring negative consequences such as mental health concerns caused by pressures. DeDeyn (2008) on the other hand, defined academic stress as a situation caused by emotional and mental pressure and tension that arise due to the requirements of university life. The author expresses the academic stress as the mental, emotional pressure, and tension that the student feels towards the expectations in school life. Academic success is of special importance for university students who are at the final stage of education before entering a profession. Students are exposed to high stress for many reasons especially in the process that covers the university preparatory period in a private vocational field (Calaguas, 2011).

Individuals aim to do their best to develop their abilities positively, in order to reveal their potentials, without worrying about whether standard criteria are equal for all candidates. Thus, individuals try to minimize stressors around them. Therefore, individuals' success goals are determined by comparing them with their competitors and gaining superiority in the criteria previously determined (Arends \& Kilcher, 2010). In order to be successful, it is not enough for individuals to set goals, but they also need to be commitment to this goal. Goal commitment is defined as "the individual's determination and perseverance to reach his goal" (Locke \& Latham, 1990). Commitment is an essential condition for goal setting to be successful. In any context, if individuals strive towards the same goal, the individual who adopts his goal and turns it into behavior and is committed to this goal can be one step ahead of his competitors (Tugay \& Aktar, 2019).

In this study, answers to the following Research Questions were sought by addressing the phenomenon of stress and goal commitment experienced by pre-service teachers during the education process:

RQ1. Are there any differences in the stress levels and goal commitment variables of pre-service teachers in terms of gender, department, and academic grade point average?

RQ2. Is there a relationship between "goal commitment scores" and "stress scores towards the academic expectations" of the pre-service teachers?

\section{Methodology}

2.1. Sample Size

In this study, a total of 295 female and 170 male pre-service teachers (students who are not yet teaching professionally) studying at Mugla Sitki Kocman University, a state university in Turkey, voluntarily participated.

\subsection{Measurement Instruments}

To measure goal commitment, the Goal Commitment Scale developed by Hollenbeck et al. (1989) in 9 items, later revised in 5 items by Senel. and Yıldız (2016) and finally adapted to Turkish by Senel. and Yıldız (2016) was used. Scale statements were measured with a 5 -point Likert rating ( $1=$ Strongly disagree, $5=$ Strongly agree). To measure the academic expectation stress of the participants, the Academic Expectations Stress Inventory developed by Ang and Huan (2006) and later adapted to Turkish by Akin et al. (2009) was used. This scale has two subdimensions called expectations of parents/teachers ( 5 items) and expectations of self (4 items). Scale statements were measured with a 5 -point Likert rating ( $1=$ Strongly disagree, $5=$ Strongly agree). 


\subsection{Statistical Analysis}

The data obtained were analyzed using the SPSS 22.0 Windows program. The demographic and educational information of the participants were analyzed with descriptive statistics (percentage and frequency).

The reliability of "the expectations of parents/teachers" sub-dimension of the Academic Expectations Stress Inventory was found to be 0.836 , for "the expectations of self" sub-dimension was found to be 0.734 . The reliability of the Goal Commitment scale was found to be 0.720. These values indicate that all the scales are highly reliable.

Independent T-test was used to compare the scale scores by gender, and One Way ANOVA analysis was used to compare the department and overall academic grade averages. Pearson Correlation analysis was used to determine the relationships between the variables, and Simple Linear Regression analysis was used to determine the effect of Goal Commitment on the sub-dimensions of Academic Expectations Stress Inventory.

\section{Findings / Results}

The findings obtained from the analyses conducted within the framework of the purpose of the study are presented in tables and the values are interpreted.

Table-1. Frequency and percentage distributions for gender and education information of the participants.

\begin{tabular}{|c|c|c|c|}
\hline Variables & Categories & f & $\%$ \\
\hline \multirow{2}{*}{ Gender } & Female & 295 & 63.4 \\
\hline & Male & 170 & 36.6 \\
\hline \multirow{9}{*}{ Department } & Physical Education and Sports Teaching & 60 & 12.9 \\
\hline & Computer and Teaching Tech & 50 & 10.8 \\
\hline & Educational Sciences & 50 & 10.8 \\
\hline & Fine Arts & 50 & 10.8 \\
\hline & Mathematics and Science & 50 & 10.8 \\
\hline & Special Education & 50 & 10.8 \\
\hline & Social Sciences and Turkish & 50 & 10.8 \\
\hline & Basic Training & 50 & 10.8 \\
\hline & Foreign Languages & 55 & 11.8 \\
\hline \multirow{3}{*}{$\begin{array}{l}\text { Overall academic grade } \\
\text { point average }\end{array}$} & $1.00-1.99$ & 117 & 25.2 \\
\hline & $2.00-2.99$ & 226 & 48.6 \\
\hline & $3.00-4.00$ & 122 & 26.2 \\
\hline
\end{tabular}

\section{Note: $\mathrm{p}<0.01$}

Table 1 indicates that 295 (63.4\%) of pre-service teachers are female and $170(36.6 \%)$ are male. When analyzed in terms of departments, it is seen that $12.9 \%$ of participants are pre-service teachers of the Physical Education and Sports Teaching Department. In addition, $10.8 \%$ are pre-service teachers in the Computer and Teaching Tech Department, $10.8 \%$ are pre-service teachers in the Educational Sciences Department, $10.8 \%$ are pre-service teachers in the Fine Arts Department, 10.8\% are pre-service teachers in the Mathematics and Science Department, $10.8 \%$ are pre-service teachers in the Special Education Department, $10.8 \%$ are pre-service teachers in the Social Sciences and Turkish Department, 10.8\% are pre-service teachers in the Basic Training Department, and $11.8 \%$ are pre-service teachers in the Foreign Languages Department. According to the general academic grade point variable, the overall academic grade point average of $25.2 \%$ of pre-service teachers is between $1.00-1.99,48.6 \%$ of them is between $2.00-2.99$, and $26.2 \%$ of them is between $3.00-4.00$.

Table-2. Descriptive Statistics of the Academic Expectations Stress Inventory and Goal Commitment Scores.

\begin{tabular}{l|c|c|c}
\hline Scale & $\mathbf{N}$ & $\mathbf{X}$ & \multicolumn{1}{c}{ Sd } \\
\hline Expectations of parents/teachers (AESI) & 465 & 4.26 & .745 \\
\hline Expectations of self(AESI) & 465 & 3.89 & .846 \\
\hline Goal Commitment & 465 & 4.38 & .730 \\
\hline
\end{tabular}

Note: AESI = Academic Expectations Stress Inventory

Table 2 shows that pre-service teachers' stress level towards expectations of parents/teacher is at a high level, the stress level of expectations of self is above the medium level but close to the high level, and their goal commitment levels are high.

Table-3. Comparison of Academic Expectations Stress Inventory and Goal Commitment Scale Scores in Terms of Gender Variable.

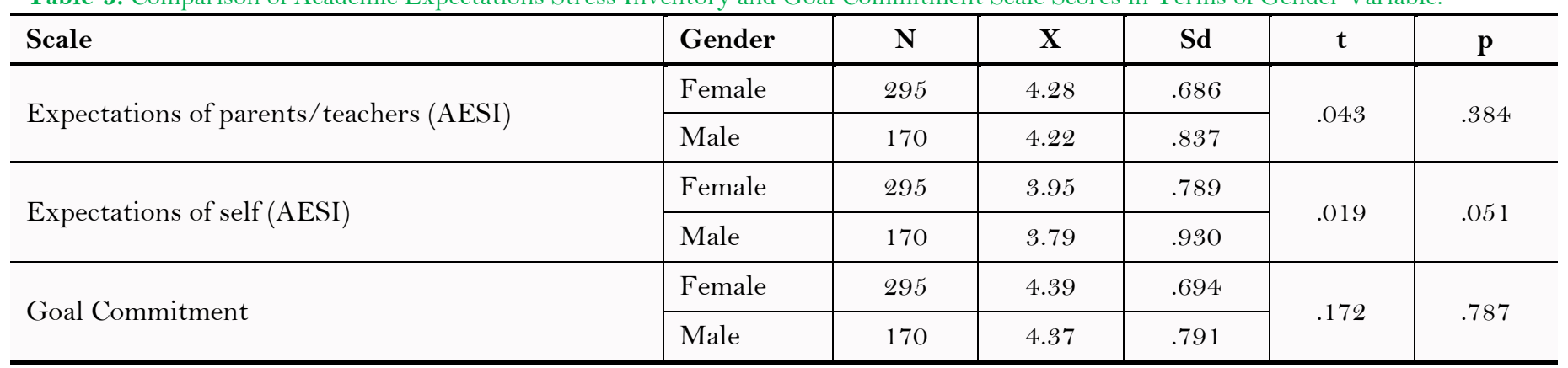

Note: AESI = Academic Expectations Stress Inventory 
According to the gender variable, Table 3 shows that there are no statistically significant differences in the stress levels of expectations of parents/teachers, stress levels of expectations of self, and goal commitment levels $(\mathrm{p}>0.05)$.

Table-4. Comparison of Academic Expectations Stress Inventory and Goal Commitment Scale Scores in Terms of Department Variable.

\begin{tabular}{|c|c|c|c|c|c|c|}
\hline Scale & Department & $\mathbf{N}$ & $\mathbf{X}$ & Sd & $\mathbf{F}$ & $\mathbf{p}$ \\
\hline \multirow{9}{*}{$\begin{array}{l}\text { Expectations of } \\
\text { parents/teachers } \\
\text { (AESI) }\end{array}$} & Physical Education and Sports Teaching & 60 & 4.48 & .671 & \multirow{9}{*}{1.714} & \multirow{9}{*}{.093} \\
\hline & Computer and Teaching Tech & 50 & 4.40 & .648 & & \\
\hline & Educational Sciences & 50 & 4.15 & .921 & & \\
\hline & Fine Arts & 50 & 4.15 & .802 & & \\
\hline & Mathematics and Science & 50 & 4.26 & .752 & & \\
\hline & Special Education & 50 & 4.23 & .613 & & \\
\hline & Social Sciences and Turkish & 50 & 4.10 & .731 & & \\
\hline & Basic Training & 50 & 4.15 & .804 & & \\
\hline & Foreign Languages & 55 & 4.35 & .687 & & \\
\hline \multirow{9}{*}{$\begin{array}{l}\text { Expectations of self } \\
\text { (AESI) }\end{array}$} & Physical Education and Sports Teaching & 60 & 4.09 & .805 & \multirow{9}{*}{2.554} & \multirow{9}{*}{$.010^{*}$} \\
\hline & Computer and Teaching Tech & 50 & 4.10 & .751 & & \\
\hline & Educational Sciences & 50 & 3.80 & .905 & & \\
\hline & Fine Arts & 50 & 3.51 & 1.101 & & \\
\hline & Mathematics and Science & 50 & 3.76 & .985 & & \\
\hline & Special Education & 50 & 4.03 & .622 & & \\
\hline & Social Sciences and Turkish & 50 & 3.91 & .737 & & \\
\hline & Basic Training & 50 & 3.91 & .728 & & \\
\hline & Foreign Languages & 55 & 3.87 & .787 & & \\
\hline \multirow{9}{*}{ Goal Commitment } & Physical Education and Sports Teaching & 60 & 4.69 & .648 & \multirow{9}{*}{3.124} & \multirow{9}{*}{$.002^{* *}$} \\
\hline & Computer and Teaching Tech & 50 & 4.39 & .650 & & \\
\hline & Educational Sciences & 50 & 4.35 & .730 & & \\
\hline & Fine Arts & 50 & 4.16 & .764 & & \\
\hline & Mathematics and Science & 50 & 4.21 & .984 & & \\
\hline & Special Education & 50 & 4.55 & .503 & & \\
\hline & Social Sciences and Turkish & 50 & 4.32 & .873 & & \\
\hline & Basic Training & 50 & 4.22 & .679 & & \\
\hline & Foreign Languages & 55 & 4.47 & .517 & & \\
\hline
\end{tabular}

Note: AESI = Academic Expectations Stress Inventory; ${ }^{* *} \mathrm{p}<0.01 ;{ }^{*} \mathrm{p}<0.05$

Table 4 indicates that there is no statistically significant difference in the stress levels of expectations of parent/teacher according to the departments of pre-service teachers ( $>0.05)$. On the other hand, it is seen that there are statistically significant differences in the stress levels of the expectations of self, and goal commitment levels of pre-service teachers $(\mathrm{p}<0.05)$. Post-Hoc Tukey test was applied to determine from which groups the significant differences originated. According to these test results, in the "expectations of self" variable, the stress levels of pre-service teachers in Physical Education and Sports Teaching, Computer and Teaching Tech, and Special Education Departments were found to be significantly higher than those in the Fine Arts Department $(\mathrm{p}<0.05)$. According to the Post-Hoc Tukey test results of the "goal commitment" variable, it was observed that the goal commitment levels of pre-service teachers in the Physical Education and Sports Teaching Department were significantly higher than those in the Fine Arts, Mathematics and Science, and Basic Training Departments $(\mathrm{p}<0.05)$.

Table-5. Comparison of Academic Expectations Stress Inventory and Goal Commitment Scale Scores in Terms of Overall Academic Grade Averages Variable.

\begin{tabular}{|c|c|c|c|c|c|c|}
\hline Scale & Grade & $\mathbf{N}$ & $\mathbf{X}$ & Sd & $\mathbf{F}$ & $\mathbf{p}$ \\
\hline Expectations of parents/teachers (AESI) & $2.00-2.99$ & 226 & 4.29 & .718 & 1.356 & .259 \\
\hline \multirow[b]{2}{*}{ Expectations of self (AESI) } & $1.00-1.99$ & 117 & 3.68 & .997 & \multirow[b]{2}{*}{5.143} & \multirow[b]{2}{*}{$.006^{* *}$} \\
\hline & $2.00-2.99$ & 226 & 3.96 & .782 & & \\
\hline \multirow{3}{*}{ Goal Commitment } & $1.00-1.99$ & 117 & 4.28 & .772 & \multirow{3}{*}{1.688} & \multirow{3}{*}{.186} \\
\hline & $2.00-2.99$ & 226 & 4.41 & .749 & & \\
\hline & $3.00-4.00$ & 122 & 4.44 & .642 & & \\
\hline
\end{tabular}

Note: AESI = Academic Expectations Stress Inventory; ${ }^{* *} \mathrm{p}<0.01$ 
According to the academic grade point average of the pre-service teachers, Table 5 shows that there is no statistically significant difference in the stress levels of the expectations of parents/teachers and goal commitment $(p>0.05)$. However, there is a statistically significant difference in stress levels of the "expectations of self" variable $(\mathrm{p}<0.05)$. According to the Post-Hoc Tukey test results applied to determine which groups originated from significant differences, in the "expectations of self" variable, the pre-service teachers who had a grade average of "2.00-2.99" and "3.00-4.00" were significantly higher than those with a "1.00-1.99" grade average ( $<<0.05)$.

\begin{tabular}{|c|c|c|c|c|}
\hline Variables & & $\begin{array}{l}\text { Expectations of } \\
\text { parents/teachers }\end{array}$ & Expectations of self & Goal Commitment \\
\hline \multirow{3}{*}{$\begin{array}{l}\text { Expectations of } \\
\text { parents/teachers }\end{array}$} & $r$ & 1 & & \\
\hline & $\mathrm{p}$ & & & \\
\hline & $\mathrm{N}$ & 465 & & \\
\hline \multirow{3}{*}{ Expectations of self } & $\mathrm{r}$ & $.592^{* *}$ & 1 & \\
\hline & $p$ & .000 & & \\
\hline & $\mathrm{N}$ & 465 & & \\
\hline \multirow{3}{*}{ Goal Commitment } & $r$ & $.431^{* *}$ & $.332^{* *}$ & 1 \\
\hline & $\mathrm{p}$ & .000 & .000 & \\
\hline & $\mathrm{N}$ & 465 & 465 & \\
\hline
\end{tabular}

Note: $\mathrm{p}<0.01$

Table 6 indicates that there is a positive and moderately significant relationship between pre-service teachers' goal commitment levels and expectations of parent/teacher stress levels $(\mathrm{r}=.431 ; \mathrm{p}<0.05)$. In addition, there is a positive and low level of a significant relationship between goal commitment levels and stress levels of expectations of $\operatorname{self}(\mathrm{r}=.332 ; \mathrm{p}<0.05)$.

Table-7. Regression Analysis Results of the Effect of the Goal Commitment on "Expectations of Parents/Teachers" Sub-Dimension of the Academic Expectations Stress Inventory

\begin{tabular}{l|c|c|c|c}
\hline Variable & B & Std. Error & $\boldsymbol{\beta}$ & $\mathbf{t}$ \\
\hline Constant & 2.332 & .190 & - & 12.275 \\
\hline Goal Commitment & .440 & .043 & .431 & 10.279 \\
\hline $\mathrm{R}=.431 ; \mathrm{R}^{2}=.186 ; \mathrm{F}(1.464)=105.66 ; \mathrm{p}=.000$ & \\
\hline
\end{tabular}

$\mathrm{R}=.431 ; \mathrm{R}^{2}=.186 ; \mathrm{F}(1.464)=105.66 ; \mathrm{p}=.000$

Note: $\mathrm{p}<0.01$.

Table 7 shows that pre-teachers' goal commitment has an explanatory effect of $18.6 \%\left(\mathrm{R}^{2}=.186\right)$ on the stress level towards the expectations of parents/teachers, and this effect is statistically significant.

Table-8. Regression Analysis Results of the Effect of Goal Commitment on "Expectations of Self” Sub-Dimension of the Academic Expectations Stress Inventory.

\begin{tabular}{l|c|c|c|c|c} 
Expectations Stress Inventory. & Std. Error & $\boldsymbol{\beta}$ & $\mathbf{t}$ & $\mathbf{p}$ \\
\hline Variable & B & .226 & - & 9.776 & .000 \\
\hline Constant & 2.207 & .051 & .332 & 7.561 & .000 \\
\hline Goal Commitment & .384 & & &
\end{tabular}

$\mathrm{R}=.332 ; \mathrm{R}^{2}=.110 ; \mathrm{F}(1.464)=57.173 ; \mathrm{p}=.000$

Note: $\mathrm{p}<0.01$.

Table 8 indicates that pre-service teachers' goal commitment has an explanatory effect of $11.0 \%\left(\mathrm{R}^{2}=.110\right)$ on the stress level towards the expectations of self, and this effect is statistically significant.

\section{Conclusion}

The results of this study indicated that pre-service teachers' stress level towards "expectations of parents/teachers" was a high level, stress level towards "expectations of self" was above the mid-level but close to the high level. Similarly, the goal commitment of pre-service teachers was high level. Since university students are in the transition phase from youth to adulthood, they face various social, professional, individual duties, and responsibilities. Particularly, students' feelings of responsibility towards their families and teachers can be shown as the reason for being under stress.

In this study, according to the gender variable, no statistically significant difference was observed in the stress levels of "expectations of parents/teachers" and "expectations of self", and "goal commitment" levels of the preservice teachers. In a study performed by Sharma and Kaur (2011) it was found the level of academic stress experienced by female students was higher than male students. Misra, Crist, and Burant (2003) in their study on 143 international student samples, investigated the reactions between the 4 structures named life stress (primary stress), academic stress factors (secondary stressor), perceived social support (stress agent), and stress factors (stress result). The results of the study indicated that there was no significant difference in academic and life stressors by gender. However, women showed higher reactions to stressors than men. Higher academic stress levels, higher life stress levels, and lower social support levels were observed. When similar studies on the subject of the research were examined, it was found that females experience higher levels of academic stress than males (Calaguas., 2013; Durak-Batigun \& Atay-Kayis, 2014; Sun, Dunne, Hou, \& Xu, 2013; Yildiz, Senel, \& Can. S, 2016). In a study conducted by Onturk, Bingol, Goksel, and Caglayan (2018) on goal commitment, there was no significant difference in the relationship between gender variable and goal commitment.

In our study, there was no statistically significant difference in the stress levels of the "expectations of parents/teachers" according to the department's variable. However, there were statistically significant differences 
in "goal commitment" and stress levels of the "expectations of self". On the other hand, it was seen that the stress level of students who were educated in Physical Education and Sports Teaching, Computer and Teaching Tech, and Special Education departments were significantly higher than the students studying in the Fine Arts department. According to the results of the goal commitment variable, it was observed that the goal commitment levels of the students studying in the Department of Physical Education and Sports Teaching were significantly higher than the students studying in the Departments of Fine Arts, Mathematics and Science, and Basic Training.

According to the academic grade point average of the pre-service teachers, there was no statistically significant difference in goal commitment and the stress levels of the expectations of parents/teachers. However, there was a statistically significant difference in stress levels of the expectations of self-variable. In the expectations of selfvariable, the pre-service teachers who had a grade average of "2.00-2.99" and "3.00-4.00" were significantly higher than those with a "1.00-1.99" grade average. Conditions such as forcing himself/herself to be "the best" or doing the "best" and expecting too much from himself/herself can be reasons that increase the stress level of pre-service teachers.

In this study, there was a positive and moderately significant relationship between pre-service teachers' goal commitment levels and expectations of parent/teacher stress levels $(\mathrm{r}=.431 ; \mathrm{p}<0.05)$. In addition, there was a positive and low level of a significant relationship between goal commitment levels and stress levels of expectations of self $(\mathrm{r}=.332 ; \mathrm{p}<0.05)$. In addition, pre-service teachers' goal commitment had an explanatory effect of $11 \%$ $\left(\mathrm{R}^{2}=.110\right)$ on the stress level towards the expectations of self, and this effect was statistically significant.

According to the results of this study, it can be said that goal commitment has a predictive effect on academic stress levels. Accordingly, it can be said that goal commitment is an effective factor on pre-service teachers and increases the level of stress towards academic expectations. According to these results, pre-service teachers should be informed about stress and informative and educational activities should be organized about ways to deal with stress.

\section{Recommendation}

In future studies, different scales of the participants can be used to investigate the stress levels of prospective teachers towards academic retention and to determine the mediator role.

\section{Limitations}

We think that not being able to determine detailed personal characteristics is one of the limitations of this study. Besides, different demographic features to be used can be added to the personal information form in order to determine the differences between the findings. Working with larger sample groups, comparing multiple branches, regions, and universities will also contribute to the literature.

\section{References}

Aihie, O. N., \& Ohanaka, B. I. (2019). Perceived academic stress among undergraduate students in a Nigerian university. Journal of Educational and Social Research, 9(2), 56-66.

Akin, A., Abaci, R., \& Cetin, B. (2009). The validity and reliability study of Turkish version of the academic expectations stress inventory. Paper presented at the 30th International Conference of the Stress and Anxiety Research Society (STAR), July, 16-18, .Budapest, Hungary.

Ang, R. P., \& Huan, V. S. (2006). Academic expectations stress inventory: Development, factor analysis, reliability, and validity. Educational and Psychological Measurement, 66(3), 522-539.Available at: https://doi.org/10.1177/0013164405282461.

Arends, R. I., \& Kilcher, A. (2010). Teaching for student learning: Becoming and accomplished teacher. New York and London: Routledge.

Barut, Y. (2019). Stress factors in secondary school students. Electronic Turkish Studies, 14(1), 121-137.

Borekci, C., \& Uyangor, N. (2018). Family attitude, academic procrastination and test anxiety as predictors of academic achievement International Journal of Educational Methodology, 4(4), 219-226.Available at: https://doi.org/10.12973/ijem.4.4.219.

Calaguas, G. M. (2011). The link between academic achievement and academic expectations stress. Journal of Education and Vocational Research, 1(3), 106-111.Available at: https://doi.org/10.22610/jevr.v1i3.16.

Calaguas., G. M. (2013). Parents/teachers and self-expectations as sources of academic stress. International Journal of Research Studies in Psychology, 2(1), 43-52.

DeDeyn, R. (2008). A comparison of academic stress among Australian and international students. UW-L Journal of Undergraduate Research., $11(4), 1-4$.

Durak-Batigun, A., \& Atay-Kayis, A. (2014). Stress factors among university students: A study on interpersonal relationship style and problem solving abilities. Hacettepe University Journal of Education, 29(2), 69- 80.

Epstein, J. L. (2018). School, family, and community partnerships: Preparing educators and improving schools. New York: Routledge.

Hollenbeck, J. R., Klein, H. J., O'Leary, A. M., \& Wright, P. M. (1989). Investigation of the construct validity of a self-report measure of goal commitment. Journal of Applied Psychology, 74(6), 951-956.

Kadapatti, M. G., \& Vijayalaxmi, A. (2012). Stressors of academic stress-a study on pre-university students. Indian Journal of Scientific Research, 3(1), 171-175

Kalkin, E. G. (2017). Perception of glass ceiling effect on stress level of women working in state and private banks. International Periodical for the Languages, Literature and History of Turkish or Turkic, 12(3), 341-354.

Kennerley, H. (2017). Overcoming anxiety. Translation. Yener, Nur, Kaygi: Kuraldisi Publishing.

Klein, H. J., Wesson, M. J., Hollenbeck, J. R., Wright, P. M., \& DeShon, R. P. (2001). The assessment of goal commitment: A measurement model meta-analysis. Organizational Behavior and Human Decision Processes, 85(1), 32-55.Available at: https://doi.org/10.1006/obhd.2000.2931.

Locke, E. A., \& Latham, G. P. (1990). A theory of goal setting and task performance. Englewood Cliffs, NJ: Prentice-Hall.

Misra, R., Crist, M., \& Burant, C. J. (2003). Relationships among life stress, social support, academic stressors, and reactions to stressors of international students in the United States. International Journal of Stress Management, 10(2), 137-157.Available at: https://doi.org/10.1037/1072-5245.10.2.137.

Onturk, Y., Bingol, E., Goksel, A. G., \& Caglayan, A. (2018). Investigation of corporate target donations of administrative staff at university. Journal of Social and Humanities Sciences Research, 5(30), 4016-4021.

Senel., E., \& Yıldız, M. (2016). Goal commitment scale: Turkish adaptation, validity and reliability in students studying in the field of physical education and sport. CBU Journal of Physical Education and Sport Sciences, 11(2), 58-65.

Sengul, O., Zhang, X., \& Leroux, A. J. (2019). A multi-level analysis of students' teacher and family relationships on academic achievement in schools. International Journal of Educational Methodology, 5(1), 117-133.Available at: https://doi.org/10.12973/ijem.5.1.131.

Senol, F. B., \& Turan, F. (2019). Teacher rating scales of early academic competence (TRS-EAC): Adaptation to Turkish, validity and reliability. International Journal of Educational Methodology, 5(1), 43-57.Available at: https://doi.org/10.12973/ijem.5.1.43. 
Sharma, M., \& Kaur, G. (2011). Gender differences in Procrastination and Academic Stress among adolescents. Indian Journal of Social Science Researches, 8(1-2), 122-127.

Sun, J., Dunne, M. P., Hou, X.-y., \& Xu, A.-q. (2013). Educational stress among Chinese adolescents: Individual, family, school and peer influences. Educational Review, 65(3), 284-302.Available at: https://doi.org/10.1080/00131911.2012.659657.

Tekin, E., Cilesiz, Z. Y., \& Gede, S. (2019). A research on the ways of coping with stress and perceived stress levels of employees in different professions. Ordu University Journal of Social Science Research, 9(1), 79-89.

Tugay, O., \& Aktar, A. (2019). Effects of level of satisfaction level of university students on career targets from on the job training: A research on students in accounting and financial management department. Journal of Mehmet Akif Ersoy University Economics and Administrative Sciences Faculty, 5(3), 867-881.

Yildiz, M., Senel, E., \& Can. S. (2016). Investigation of pre-service teachers' perception of academic support and stress levels towards academic expectations. Trakya University Journal of Social Sciences, $18(1), 271-282$. 